\title{
A LEI ORÇAMENTÁRIA ANUAL COMO VIA DE CONCRETIZAÇÃO DO DIREITO FUNDAMENTAL AO DESENVOLVIMENTO E AS QUESTÕES HERMENÊUTICAS SOBRE A (IM)POSSIBILIDADE DE SUA REJEIÇÃO TOTAL
}

\author{
THE ANNUAL BUDGET LAW AS A WAY TO ACHIEVE FUNDAMENTAL RIGTH TO \\ DEVELOPMENT AND HERMENEUIC ISSUES ON THE (IM) POSSIBILITY OF ITS TOTAL \\ REJECTION
}

\section{José Eduardo Costa Devides}

Doutorando em Direito pela Universidade de Marília. Controlador Interno da Câmara Municipal de Jaú/SP.

E-mail: du.devides@gmail.com

\section{Mariana Ribeiro Santiago}

\begin{abstract}
Pós-Doutorado em Direito pela Justus-Liebig-Universität Gießen (Alemanha). Doutorado e Mestrado em Direito pela Pontifícia Universidade Católica de São Paulo - PUCSP. Professora do Programa de Pós-Graduação em Direito da Universidade de Marília. Editora-Chefe da Revista Argumentum. Advogada. E-mail: mariana@nbsadvogados.com.br
\end{abstract}

Recebido em: 09/09/2019 Aprovado em: 15/04/2020

RESUMO: O tema do presente artigo analisa a repercussão jurídica sobre a possibilidade de rejeição total do projeto de lei orçamentária anual. O problema de pesquisa refere-se à violação de princípios e ao direito fundamental ao desenvolvimento quando se opera a rejeição total do projeto da LOA. O objetivo é analisar se tal hipótese se sustenta, do ponto de vista hermenêutico, ou se colocaria em risco o desenvolvimento da coletividade. Em conclusão, constatou-se que, pela aplicação do princípio da eficiência, não é possível a rejeição total da LOA, pois traria prejuízos de ordem econômica e organizacional ao Poder Legislativo, assim como inviabilizaria o desenvolvimento momentâneo da coletividade. O método de abordagem adotado é o dedutivo, combinado com o método de pesquisa bibliográfico, sem prejuízo da contribuição de análise de jurisprudência.

Palavras-chave: Lei Orçamentária Anual. Rejeição Total. Princípios. Eficiência. Desenvolvimento.

\begin{abstract}
The theme of this article analyzes the legal repercussion on the possibility of total rejection of the annual budget bill. The research problem refers to the violation of principles and the fundamental right to development when operating the total rejection of the LOA project. The objective is to analyze whether this hypothesis is supported, from the hermeneutical point of view,
\end{abstract}


or if the development of the collectivity would be in risk. In conclusion, it was found that by applying the principle of efficiency, the total rejection of the LOA is not possible, as it would bring economic and organizational damages to the Legislative Power, as well as making the momentary development of the unfeasible community. The method of approach adopted is the deductive, combined with the bibliographic method of research, without prejudice to the contribution of case law analysis.

Keywords: Annual Budget Law. Total Rejection. Principles. Efficiency. Development.

SUMÁRIO: Introdução; 1. A lei orçamentária anual, os seus princípios e a concretização do direito fundamental ao desenvolvimento; 2 . A inconstitucionalidade de dispositivos que tratam sobre a rejeição da LOA em leis orgânicas: os casos das Leis Orgânicas de Rio das Flores/RJ e de São Tiago/MG; 3. A possibilidade de rejeição total da lei orçamentária anual: uma ponderação entre a utilização da interpretação literal do $\S 8^{\circ}$, do art. 166, da Constituição Federal ou da interpretação sistemática; Conclusões; Referências Bibliográficas.

\section{INTRODUÇÃO}

A existência humana digna (individual ou coletiva) clama por um plano governamental capaz de suprir as necessidades inerentes à sobrevivência, desde à época em que se passou a reconhecer os governantes como representantes da população, num quadro de Estado Democrático de Direito.

No ordenamento jurídico brasileiro, para que haja a concretização de alguns direitos fundamentais básicos, como à saúde, o esporte, a educação e o lazer (que devem ser garantidos aos indivíduos, nos termos do que define o art. $5^{\circ}$ da Constituição Federal), a primeira etapa a se percorrer é o planejamento das metas e a delimitação do valor monetário a ser investido em cada área. O início deste ciclo compreende a elaboração cuidadosa de um plano que objetiva o desenvolvimento da coletividade: o projeto da lei orçamentária anual.

O problema do presente trabalho pauta-se nas consequências de o Poder Legislativo rejeitar totalmente o projeto da LOA. Existe, de fato, a possibilidade jurídica de rejeição total do projeto da LOA? Quais as consequências que decorrem deste ato? Tal possibilidade tem de ser interpretada somente sob o enfoque da literalidade prevista no $\S 8^{\circ}$, do art. 166 , da Constituição Federal, ou sistematicamente, à luz do que determinam outros dispositivos constitucionais, legais e alguns princípios?

A justificativa da pesquisa baseia-se na importância da aprovação, ano a ano, da lei orçamentária de cada ente, com a avaliação realista da situação orçamentária, para que sejam supridas as necessidades momentâneas da população dentro do ano referência do projeto, favorecendo, assim, ao desenvolvimento das cidades.

Ademais, o objetivo deste trabalho é o de contribuir para que seja evitada a interpretação sobre a possibilidade jurídica de rejeição, in totum, da LOA, em obediência a princípios constitucionais, legais e ao direito fundamental ao desenvolvimento.

Para tanto, inicialmente se trata dos principais aspectos da lei orçamentária anual, seus princípios e a concretização do direito fundamental ao desenvolvimento. Após isso, o estudo se volta para dispositivos idênticos nas Leis Orgânicas de Rio das Flores/RJ e de São Tiago/MG, acerca da rejeição da LOA em leis orgânicas. Por fim, explana-se sobre a possibilidade de rejeição total da lei orçamentária anual, considerando os métodos de interpretação possíveis para a leitura do $\S 8^{\circ}$, do art. 166, da Constituição Federal.

A presente pesquisa será desenvolvida à luz do método de abordagem dedutivo, partindose da regra geral, insculpida na Constituição Federal, para a análise dos casos concretos. $\mathrm{Na}$ 
pesquisa, os métodos utilizados são o bibliográfico, envolvendo livros e revistas especializadas, sem prejuízo da contribuição da análise de jurisprudência, na perspectiva documental.

\section{A LEI ORÇAMENTÁRIA ANUAL E OS SEUS IMPACTOS NO DIREITO FUNDAMENTAL AO DESENVOLVIMENTO}

O desenvolvimento foi consagrado como um direito humano na Resolução $n^{\circ} 41 / 128$ da Assembleia Geral das Nações Unidas, a denominada Declaração sobre Direito ao Desenvolvimento, a qual dispõe: a) o desenvolvimento engloba um processo econômico, social, cultural e político, que objetiva o bem-estar de toda a população; b) os Estados devem proporcionar a igualdade de oportunidade para todos no acesso aos recursos básicos, educação, serviços de saúde, alimentação, habitação, emprego e distribuição equitativa da renda, bem como tomar medidas que assegurem que as mulheres tenham um papel ativo no processo de desenvolvimento (art. $8^{\circ}, \S 1^{\circ}$ ); e c) os Estados deverão garantir o pleno exercício e o fortalecimento progressivo do direito ao desenvolvimento, incluindo a formulação, a adoção e a implementação de políticas, medidas legislativas e outras, em níveis nacional e internacional (art. 10) (ORGANIZAÇÃO DAS NAÇÕES UNIDAS, 1986).

Constata-se que a referida Resolução disciplinou que ao Estado é incumbida a missão de garantir o desenvolvimento através da formulação de políticas públicas, medidas legislativas, dentre outras formas, com o fito de garantir a igualdade de oportunidade a todos os membros da sociedade e permitir o acesso aos direitos essenciais a subsistência do indivíduo (educação, saúde, alimentação, habitação, emprego, entre outros).

Sobre a referida Declaração, Vladmir Oliveira da Silveira e Samyra Haydée Dal Farra Naspolini (2013. pp. 127-128) afirmam que

[...] foi a partir desse documento que o direito ao desenvolvimento se configurou como um direito humano inalienável e passou a ser entendido como um processo global econômico, social cultural e político, que tende ao melhoramento constante de toda a condição e qualidade de vida da população e dos indivíduos, sob a base de sua participação ativa, livre e significativa no processo de desenvolvimento e na distribuição dos benefícios de que dele derivam [...]. Ficou assim estabelecido que o principal responsável - ou seja, o sujeito passivo do direito ao desenvolvimento - é o Estado; isto é, é ele que tem o dever de criar as condições favoráveis ao desenvolvimento supranacional e interno dos povos e dos indivíduos.

O conceito de desenvolvimento, historicamente, mostrou-se atrelado ao poder políticomilitar, ao poder econômico ou, conforme observado especificamente ao longo do Século XX, ao crescimento econômico. O desafio que se apresenta para o novo século é exatamente transcender tais limitações teóricas, numa abordagem transdisciplinar, de amálgama, econômica, jurídica etc., observando o desenvolvimento como um todo (BARRAL, 2005, p. 32. SEN, 2005, p. 17. CAMPELLO; SANTIAGO; ANDRADE, 2018, p. 9).

No plano nacional, o desenvolvimento nacional é citado no preâmbulo e no art. $3^{\circ}$, II, da Constituição Federal, como objetivo da República Federativa do Brasil. A par disso, entende-se que este é um direito fundamental que decorre do $\S 2^{\circ}$, do art. $5^{\circ}$, da Carta Magna, haja vista que os direitos e garantias expressos na Constituição "não excluem outros decorrentes do regime e dos princípios por ela adotados, ou dos tratados internacionais em que a República Federativa do Brasil seja parte" (BRASIL, 1988).

Pode-se depreender, ainda, que o direito ao desenvolvimento se encontra enraizado no inciso I, do art. $3^{\circ}$, da Constituição Federal, que aborda todas as dimensões dos direitos 
fundamentais ao estabelecer que são objetivos fundamentais da República Federativa do Brasil a construção de uma sociedade livre, justa e solidária (BRASIL, 1988).

Verifica-se que o desenvolvimento visa à realização da dignidade da pessoa humana, e não de maneira coincidente estende-se a vários aspectos, como os de naturezas política, social, cultural, ambiental, dentre outros (DEVIDES; SILVEIRA, 2017). De acordo com Martinelli,

se o Estado dá efetividade ao direito ao desenvolvimento por meio de políticas públicas de modo que a dignidade humana dos administrados seja respeitada, temse como consequência o engrandecimento do ser humano e a sua inclusão no meio social, conferindo-lhe então mais oportunidades e mais autodeterminação, de modo que, este mesmo administrado não poderá então alegar uma pretensa "hipossuficiência culpante" ou, vulnerabilidade, no momento de sua conduta delitiva, pois a sua autodeterminação terá sido preenchida pelo agir estatal. (MARTINELLI, 2013, p. 410)

Expoente sobre o tema do desenvolvimento, Amartya Sen ensina que o desenvolvimento é um processo de expansão das liberdades das pessoas e remoção de suas principais fontes de privação, que são a "pobreza e tirania, carência de oportunidades econômicas e destituição social sistemática, negligência dos serviços públicos e intolerância ou interferência excessiva de Estados repressivos" (2010, p. 16-17).

Nessa perspectiva, pode-se afirmar que é fundamental para a efetivação do direito humano ao desenvolvimento a perfeita elaboração da lei orçamentária (com as emendas pertinentes do Poder Legislativo, a ampla transparência, as audiências pública e a fiscalização por parte dos órgãos de controle e da população), tendo a missão, dentre outras, de colaborar para erradicar a pobreza, estimular as oportunidades econômicas e garantir as liberdades individuais e coletivas.

O sistema orçamentário representa um conjunto de ações que objetivam, resumidamente, o planejamento e a execução das finanças públicas. Não obstante existam, hodiernamente, três peças que disciplinam o orçamento público - plano plurianual (PPA), lei de diretrizes orçamentárias (LDO) e lei orçamentária anual (LOA) - este trabalho depositará os seus esforços na lei orçamentária anual, para fins de melhor aprofundamento do tema.

A lei orçamentária anual possui grande importância para a concretização de direitos essenciais à coletividade. É por intermédio dela que os direitos relativos à saúde, à educação, ao meio ambiente, à habitação, dentre outros, são programados e, em momento posterior (quando da operacionalização das metas previstas na peça orçamentária), colocados em prática. Conforme consigna Aliomar Baleeiro,

Nos Estados democráticos, o orçamento é considerado o ato pelo qual o Poder Legislativo prevê e autoriza ao Poder Executivo, por certo período e em pormenor, as despesas destinadas ao funcionamento dos serviços públicos e outros fins adotados pela política econômica ou geral do País, assim como a arrecadação das receitas já criadas em lei (BALEEIRO, 1969, p. 396).

É o planejamento das finanças públicas que se traduz na LOA. Se na vida privada, em cada família, têm-se o planejamento do quanto se ganha e o montante que será gasto pelas despesas decorrentes das necessidades básicas e lazer, na vida pública não poderia ser diferente, ainda mais em se tratando de milhares de pessoas que contribuem com uma parcela das suas próprias rendas.

A Constituição Federal, no $\S 6^{\circ}$, do art. 165, estabelece que compete ao Poder Executivo a lei orçamentária anual, compreendendo as seguintes espécies de orçamento: o orçamento fiscal referente aos Poderes da União, seus fundos, órgãos e entidades da administração direta e indireta, inclusive fundações instituídas e mantidas pelo Poder Público; o orçamento de investimento das empresas em que a União, direta ou indiretamente, detenha a maioria do capital social com direito 
a voto; e o orçamento da seguridade social, abrangendo todas as entidades e órgãos a ela vinculados, da administração direta ou indireta, bem como os fundos e fundações instituídos e mantidos pelo Poder Público (BRASIL, 1988).

Sendo a principal peça do trio, o orçamento fiscal refere-se aos Poderes, seus fundos, órgãos e entidades da administração direta e indireta, inclusive fundações instituídas pelo poder público. A administração indireta compreende quatro categorias de entidades: autarquias, fundações públicas, empresas púbicas e sociedades de economia mista. Contudo, apenas integram o orçamento fiscal as autarquias, as fundações, parte das empresas públicas e algumas sociedades de economia mista (GIACOMONI, 2012). É a natureza jurídica de cada entidade e a necessidade de dependerem dos recursos transferidos pelo Tesouro que irá determinar a obrigatoriedade de integrarem o orçamento fiscal.

De acordo com a Constituição Federal, o orçamento de investimento de empresas compreende os investimentos realizados pelas empresas em que o Poder Público, direta ou indiretamente, detenha a maioria do capital social com voto. Assim, "o orçamento deixa de lado as receitas e despesas operacionais, abrangendo apenas os investimentos das empresas estatais" (GIACOMONI, 2012, p. 231).

O orçamento da seguridade social agrega as entidades e órgãos a ela vinculados (a saúde, a previdência social e a assistência social), da administração direta e indireta, assim como os fundos e fundações instituídos e mantidos pelo poder público. "Trata-se, aqui, de um orçamento de áreas funcionais, que cobre todas as despesas classificáveis como de seguridade social e não apenas as entidades e órgãos da seguridade social" (GIACOMONI, 2012, p. 231).

Compreendendo estes três seguimentos, o orçamento anual deve possuir, "exclusivamente, a previsão da receita e a fixação da despesa: nenhum dispositivo estranho a esses conceitos deve ser nele introduzido" (MARTINS; GODOY, 2012, p. 201). Aliás, a realização da peça orçamentária exige compatibilidade ao plano plurianual, à lei de diretrizes orçamentárias e diretamente ao programa anual de governo. A modificação do orçamento anual (no curso da execução orçamentária) só pode ser efetivada por lei, mediante quorum qualificado (MARTINS; GODOY, 2012, p. 202).

Como já salientado, a iniciativa do projeto da LOA é do Poder Executivo, que deverá encaminhá-lo para apreciação do Poder Legislativo dentro do prazo fixado na legislação, constituindo crime de responsabilidade a não apresentação até tal data.

Seguindo o trâmite ordinário, quando apresentado o projeto ao Legislativo (e, neste caso, trabalhar-se-á sob a esfera municipal), o mesmo será encaminhado à Comissão Permanente de Finanças, Orçamento e Economia (que se equipara, à nível federal, com a comissão mista de Deputados e Senadores) para o exame e a emissão de parecer sobre tais matérias de sua competência. Caberá, igualmente, à mesma comissão receber as emendas, consignando o parecer para posterior apreciação do plenário do Legislativo.

A possibilidade de apresentação de emendas encontra respaldo nos $\S \S 3^{\circ}$ e $4^{\circ}$, do art. 166 da Constituição Federal, sendo bem amplo o poder de atuação dos parlamentares. $\mathrm{O} \S 6^{\circ}$, do referido artigo, ainda faculta ao Presidente da República enviar mensagem modificativa dos projetos de lei, desde que não tenha sido iniciada a votação na comissão mista (que, repise-se, equivale à Comissão de Finanças, na esfera municipal), da parte cuja alteração é proposta (HARADA, 2009, p. 61).

No mais, importante mencionar que é essencial ao processo de criação da lei orçamentária anual a participação da sociedade em audiência pública, para que eventuais sugestões ou críticas possam, de alguma forma, serem transformadas em texto de lei. A consciência da sociedade sobre os instrumentos orçamentários é uma questão de cidadania, permitindo-se a participação no direcionamento das despesas públicas e a fiscalização sobre a sua fiel execução (HARADA, 2009, p. 61). 
Ademais, importante discorrer sobre a necessidade de o orçamento público obedecer a um conjunto de princípios orçamentários. Dentre tantos princípios que irradiam o orçamento público, esta pesquisa focará apenas nos principais, que costumam aparecer com maior frequência na doutrina.

A lei das finanças públicas (Lei n. ${ }^{\circ} 4.320 / 64$ ) é o primeiro caminho a se perseguir tais princípios, haja vista que, já no artigo $2^{\circ}$, identifica-se a previsão de três deles: unidade, universalidade e anualidade.

O primeiro deles, unidade, que também encontra respaldo no $\S 5^{\circ}$, do art. 165 , da Constituição Federal, estabelece que o orçamento deve ser uno, noutros termos, deve existir apenas um orçamento para determinado exercício financeiro. "Dessa forma integrado, é possível obter eficazmente um retrato geral das finanças públicas e, o mais importante, permite-se ao Poder Legislativo o controle racional e direto das operações financeiras de responsabilidade do Executivo" (GONTIJO, 2004).

A universalidade compreende a necessidade de o orçamento ser composto por todas as receitas e despesas, inclusive, pelos seus valores brutos, não comportando quaisquer deduções. A descrição pormenorizada de todos os gastos, na LOA, é de grande valia para o combate à corrupção, pois auxilia os órgãos de controle a internalizarem as informações de forma mais simples, assim, contribui para a perfeita efetividade do trabalho de fiscalização.

O princípio da anualidade determina que a lei orçamentária deve ser renovada a cada ano, pois a peça deve se adequar à realidade financeira de cada localidade, em determinado período de tempo, evitando, assim, o impacto da instabilidade dos fatores políticos, econômicos e sociais (MEIRELLES, 2017, p. 293)

Nunca é demais lembrar que, no Brasil, assim como em diversos países do mundo, o ano financeiro coincide com o ano civil, de acordo com o que estabelece o art. 34, da Lei das Finanças Públicas.

Outros princípios que se relacionam ao orçamento são o da legalidade (pois para ter validade, a LOA precisa se transformar em lei), o do equilíbrio (as despesas fixadas devem guardar relação com as receitas estimadas), o da programação orçamentária (que traduz-se na obrigatoriedade de discriminar os gastos por meio de programas de trabalho, para que os objetivos e metas a se atingirem possam ser identificados) o da exclusividade (porque não poderá conter a LOA dispositivo estranho à previsão da receita e à fixação da despesa, como estabelece o art. 165, $\S 8^{\circ}$, da Constituição Federal) e da publicidade (ampla divulgação, incluindo a publicação do relatório resumido da execução orçamentária, segundo o art. 165, § $3^{\circ}$, da Constituição Federal) (SADECK, 2009, p. 261. HARADA, 2009, p. 70).

Por derradeiro, tem-se o princípio da não vinculação de receita, que objetiva vedar a sujeição do produto de impostos a órgão, fundo ou despesas, sendo que devem atender indiscriminadamente às necessidades da Administração (MEIRELLES, 2017, p. 294).

Dentro dessa linha de compromisso e responsabilidade do Poder Público ao planejar a gestão dos recursos públicos, é hialino que a lei orçamentária anual é uma medida que tem a finalidade de garantir o direito ao desenvolvimento, portanto, existe a necessidade do fiel cumprimento da legislação atinente ao tema (assim como do atendimento aos princípios orçamentários), da participação conjunta dos poderes da república, dos órgãos de controle e da sociedade para a sua perfeita elaboração.

\section{A REJEIÇÃO DA LOA EM LEIS ORGÂNICAS: DIVERGÊNCIA JURISPRUDENCIALL, SEGURANÇA JURÍDICA E DESENVOLVIMENTO}

A temática da rejeição da LOA em Leis Orgânicas é tema bastante polêmico e foi objeto de análise judicial em dois casos específicos, estudados no presente trabalho, referentes às Leis 
Orgânicas de Rio das Flores/RJ e de São Tiago/MG. Nota-se que, apesar do delineamento semelhante, todavia, os casos foram solucionados com motivação em teses totalmente distintas.

No primeiro deles, na LOA de Rio das Flores/RJ, o Procurador Geral de Justiça do Estado do Rio de Janeiro ajuizou ação direta de inconstitucionalidade em face do art. 142 da Lei Orgânica do Município de Rio das Flores, que possuía a seguinte redação: "Art. 142: Rejeitado pela Câmara o projeto de lei orçamentária anual, prevalecerá, para o ano seguinte, o orçamento do exercício em curso, aplicando-lhe a atualização dos valores".

A questão da inconstitucionalidade sustentada pelo voto do relator desembargador Luiz Zveiter pautou-se em suposta violação ao princípio da separação dos poderes, em razão de o referido artigo permitir a vigência de uma lei orçamentária que não resultou de um projeto apresentado pelo Poder Executivo (pelo menos no ano correspondente ao exercício do qual ele deveria ter sido analisado), assim como não obteve aprovação (com exame e oferecimento de eventuais emendas) pelo Poder Legislativo. Além da flagrante violação ao princípio da separação de poderes, tal dispositivo ainda conferia eficácia jurídica a um ato normativo já exaurido.

Imperioso salientar que a violação à separação de poderes pode causar prejuízos severos à gestação da administração pública, na medida em que permite a "politização da Justiça", que se manifesta nas hipóteses em que o Legislativo exerce a função de julgar, a "executivização legislativa", que se reflete nas diversas previsões constitucionais de elaboração de leis e atos normativos pelo Executivo e, ainda, a "judicialização da Política", revelada diante da atuação judicial quando da aplicação do direito no caso concreto, criando soluções judiciais para omissões legislativas ou legislando positivamente (BULOS, 2012, p. 251).

Este ponto, especificamente, merece uma reflexão no tocante à suposta violação à separação de poderes (e que acima foi brevemente ventilada). Ao classificar o dispositivo como duplamente violador da separação de poderes (porque prejudica a atuação dos Poderes Legislativo e Executivo), a convicção do relator parece ter sido a seguinte: com a rejeição do projeto da LOA, passa a ganhar sobrevida a lei orçamentária do exercício vigente, documento que não fora apresentado (dentro do exercício da qual deveria ser objeto de apreciação) pelo executivo, e que tampouco possui as emendas (frise-se, novamente, dentro do exercício da qual deveria ser objeto de emenda) pelo legislativo. Destarte, o próprio legislativo, além de impedir a função do poder executivo, de igual forma, estaria prejudicando o desenvolvimento de suas próprias atribuições. Da mesma forma, o relator fundamentou sua decisão alegando que a conduta de utilizar a lei orçamentária do ano anterior impediria a avaliação realista da situação orçamentária do ente federado, o que seria prejudicial ao desenvolvimento da coletividade (RIO DE JANEIRO, 2014).

De fato, é bem possível que o orçamento do exercício anterior possa não conter as reais necessidades que a população exige. Isto porque questões voltadas a economia, à saúde, à assistência social, à segurança pública, à cultura, entre outras, variam ano a ano, de acordo com a necessidade de um município.

Consabido, em nível municipal, ao determinar a fixação de despesas, por função, a lei orçamentária prevê o montante que deverá ser destinado ${ }^{1}$ ao Poder Legislativo e às Secretarias que compõem a administração municipal. Verbi gratia, em um determinado ano, pode ocorrer de ser necessário um maior investimento nas Secretarias de Saúde e Cultura, enquanto que, no ano subsequente, a necessidade se volte mais a sanar as dificuldades financeiras da secretaria de habitação e agricultura. Esse também é um fator que inviabiliza a manutenção do orçamento para o exercício vindouro. Aliás, outro contraponto que se relaciona a prejudicialidade do desenvolvimento da coletividade (e que não foi utilizado como argumento para fundamentar a ADI) é a violação ao princípio da anualidade.

Saliente-se que o princípio da anualidade possui previsão no art. $2^{\circ}$ da Lei 4.320/64: “a Lei do Orçamento conterá a discriminação da receita e despesa de forma a evidenciar a política

${ }^{1}$ De acordo com o que prevê a Lei de Responsabilidade Fiscal (Lei Complementar n. ${ }^{\circ} 101 / 2000$ ).

Revista de Direito Brasileira | Florianólopis, SC | v. 25 | n. 10 | p. 250-265 | Jan./Abr. 2020 
econômica financeira e o programa de trabalho do Governo, obedecidos os princípios de unidade universalidade e anualidade" (BRASIL, 1964). Com efeito, seguindo o dispositivo da referida lei (e que, inclusive, foi recepcionada pela Constituição Federal de 1988), existe a obrigatoriedade de a lei orçamentária ter previsão anual. Este, inclusive, é o posicionamento do doutrinador Hely Lopes Meirelles: "Se os orçamentos pudessem prolongar-se por vários anos, haveria, por certo, grande desajuste na previsão da receita e na fixação da despesa, dada a instabilidade dos fatores políticos, econômicos e sociais, que se modificam de ano para ano" (MEIRELLES, 2010, 293).

E para reforçar a tese da vigência anual da LOA, ainda é cabível a realização de uma interpretação sistemática entre a Lei n. ${ }^{\circ}$ 4.320/64 e a Constituição Federal. Isso porque o $\S 9^{\circ}$, do art. 165, da Constituição Federal, disciplina que "cabe à lei complementar dispor sobre o exercício financeiro, a vigência, os prazos, a elaboração e a organização do plano plurianual, da lei de diretrizes orçamentárias e da lei orçamentária anual”. A lei complementar, nesse caso, é a Lei 4.320/64 (também denominada Lei do Orçamento Público), que recebeu esse status ao ser recepcionada pela constituição vigente. De acordo com o art. $2^{\circ}$, da Lei do Orçamento Público, a LOA deverá obedecer ao princípio da anualidade, ou seja, ela não poderá viger por período superior a um ano.

Portanto, pelas razões acima elucidadas (utilizando, como pano de fundo o argumento relativo ao princípio da anualidade do orçamento), o art. 142, da Lei Orgânica Municipal de Rio das Flores/RJ, foi declarado inconstitucional, inclusive, para afirmar a impossibilidade da rejeição total da LOA pelo Poder Legislativo.

De outro lado, tem-se a inspeção extraordinária realizada pelo Tribunal de Contas do Estado de Minas Gerais no Município de São Tiago. Naquela oportunidade, a auditoria apontou, dentre outras irregularidades, que não houve, em 1993, a aprovação da Lei Orçamentária do exercício de 1994, em virtude de o projeto ter sido rejeitado pela Câmara Municipal.

À época houve o cumprimento do disposto no art. 123, da Lei Orgânica do Município de São Tiago, que dispunha o seguinte: "Rejeitado pela Câmara o projeto de lei orçamentária anual, prevalecerá para o ano seguinte o orçamento do exercício em curso, aplicando-se-lhe a atualização de valores". "Desta feita, o Executivo local, em obediência ao art. 123 da LOM adotou os valores globais do Orçamento de 1993, atualizando os mesmos. Verificou que foi aberto, mediante decreto, um crédito suplementar" (MINAS GERAIS, 2008).

Todavia, o parecer dos conselheiros do TC/MG mencionou que o Prefeito municipal de São Tiago contrariou o procedimento previsto no art. $166, \S 8^{\circ}$, da Constituição Federal, no caso de ocorrer rejeição do projeto de lei orçamentária anual. Segundo o aludido dispositivo, os recursos que, em decorrência de veto, emenda ou rejeição do projeto de lei orçamentária anual, ficarem sem despesas correspondentes poderão ser utilizados, conforme o caso, mediante créditos especiais ou suplementares, com prévia e especifica autorização legislativa (MINAS GERAIS, 2008).

Com efeito, o TC/MG entendeu que, uma vez rejeitada a peça orçamentária, caberia ao Chefe do Executivo Municipal administrar o Município por crédito especial, o qual exigiria lei autorizativa e decreto executivo para sua abertura, a luz do que determina o art. 42, da Lei n. ${ }^{\circ}$ 4.320/64: "os créditos suplementares e especiais serão autorizados por lei e abertos por decreto executivo" (BRASIL, 1964). Dessa forma, o TC/MG advertiu o município de São Tiago sobre a inconstitucionalidade do art. 123, da LOM, por prever conduta que não guardava simetria com o disposto no art. 166, $\S 8^{\circ}$, da Constituição Federal.

Note-se que, embora ambas as leis orgânicas possuíssem um dispositivo com a mesma redação, a fundamentação que objetivou a inconstitucionalidade de cada dispositivo foi feita de forma diversa. No primeiro caso, alegou-se a violação da separação de poderes, a prejudicialidade ao desenvolvimento da coletividade e, como pano de fundo, a anualidade do orçamento, no intuito de decidir sobre a impossibilidade de se rejeitar totalmente a lei orçamentária anual. No segundo caso, foi realizada a interpretação conforme a Constituição para indicar a possibilidade da rejeição total da LOA, empregando-se o procedimento previsto no mencionado art. $166, \S 8^{\circ}$. 
A análise dos citados casos concretos e seus pontos de divergência geram dúvidas sobre se o Poder Legislativo tem poder para rejeitar totalmente um projeto de lei, e qual seria o caminho ideal para isso, o que tem repercussão em segurança jurídica, demanda de grande importância para o desenvolvimento nacional.

O tema da segurança jurídica, de difícil definição, é necessário para que se reforce a previsibilidade das decisões e, consequentemente, a confiança no sistema jurídico, tão essencial para a credibilidade do país e o seu desenvolvimento. Segundo Recaséns Siches (1973, p. 301), a sensação de segurança equivale à sensação de pisar um solo firme, ao tempo que a impressão de insegurança equivale ao medo que falte o solo em que nos apoiamos ou o medo da queda.

Antonio-Enrique Pérez Luño (1991, p. 17) admite que a segurança constitui um desejo arraigado na vida do homem, o qual sente terror ante a insegurança de sua existência, diante da imprevisibilidade e a incerteza a que está submetido. Quando essa insegurança é provocada ou autorizada pelos Poderes Executivo, Legislativo e Judiciário, o abalo à credibilidade das instituições jurídicas tem impacto em termos de desenvolvimento.

Para colaborar na uniformização das decisões, criando critérios de decidibilidade de conflitos (FERRAZ, 2012, 63-66), é que a doutrina tridimensionalista, utilizada na presente pesquisa, propõe a análise de questões como a ora tratada dentro dos parâmetros da dogmática hermenêutica, conforme se pretende a seguir.

\section{A (IM)POSSIBILIDADE DE REJEIÇÃO TOTAL DA LEI ORÇAMENTÁRIA ANUAL: UMA ANTINOMIA REAL E SUA SOLUÇÃO.}

Não obstante o art. 166, $\S 8^{\circ}$, da Constituição Federal, tenha estabelecido, literalmente, a possibilidade plena da rejeição total da LOA, como já se verificou no capítulo anterior, é imperioso que tal questão seja analisada pelo prisma das regras de hermenêutica.

Neste ponto, cabe previamente frisar a diferenciação entre as figuras da interpretação, da integração e da aplicação da norma. A aplicação da norma se dá em decorrência da competência de um órgão ou autoridade, que impõe uma diretriz de direito num caso concreto. Antes de aplicar o direito, ou seja, antes do processo de subsunção, contudo, o órgão ou autoridade precisa interpretá-lo, ou seja, proceder à escolha, de natureza axiológica, de vários sentidos possíveis para a norma. (REALE, 2002, pp. 295-296. ENGISCH, 2001, p. 96)

Especificamente sobre interpretação, Karl Larenz ensina que

A interpretação da lei é (...) um processo de duplo sentido, em cujo decurso se conforma a situação de facto definitiva enquanto enunciado, a partir da 'situação de facto em bruto', atendendo às proposições jurídicas potencialmente aplicáveis, e se precisa o conteúdo das normas a aplicar, atendendo mais uma vez à situação de facto, tanto quanto seja necessário. (LARENZ, 1991, p. 439).

A interpretação se limita, assim, a esclarecer o sentido verdadeiro e alcance da norma, reproduzindo, em termos diversos, o pensamento já contido nela. Mas, mais que isso, é restituir sentido a um texto corrompido, numa perspectiva crítica. Nesse objetivo, existem várias técnicas interpretativas, como a gramatical, a lógica, a sistemática, a histórica, a sociológica ou teleológica, todas complementares, não se excluindo reciprocamente. Mas, se a norma apresenta lacuna, o processo de interpretação não é suficiente para preencher tal vazio, fazendo-se necessário o uso da integração. (Diniz, 2002, pp. 276-278. SAVIGNY, 2001, pp. 8-11. REALE, 2002, p. 296).

Conforme ensina Karl Engisch (2001, pp. 276 e 279),

Uma lacuna é uma incompletude insatisfatória no seio de um todo. Aplicado ao Direito, o conceito de lacuna significa que se trata de uma incompletude insatisfatória no seio de um todo jurídico. (...) As lacunas são deficiências do 
Direito positivo (do Direito legislado ou do Direito consuetudinário), apreensíveis como faltas ou falhas de conteúdo de regulamentação jurídica para determinadas situações de fato em que é de esperar essa regulamentação e em que tais falhas postulam e admitem a sua remoção através duma decisão judicial jurídicointegradora. As lacunas aparecem, portanto, quando nem a lei nem o Direito consuetudinário nos dão uma resposta imediata a uma questão jurídica.

Na classificação de Maria Helena Diniz (2002, p. 950), a qual adotamos, é possível se identificar três espécies de lacuna, quais sejam, a) a normativa, na ausência de norma para a resolução do caso; b) a ontológica, quando, havendo norma, esta não corresponda aos fatos sociais; c) a axiológica, na falta de norma justa, ou seja, se da aplicação da norma resulte uma solução insatisfatória ou injusta.

Há referência, ainda, na obra da citada autora (DINIZ, 2002, p. 279), às lacunas de conflito ou antinomias reais, que se observam na existência de várias soluções incompatíveis para a aplicação de determinada norma, deixando o julgador numa situação insustentável, porque não há solução normativa cabível ou porque não há uma solução unívoca.

No conflito analisado no presente artigo, parece clara a ocorrência de antinomia real, onde há necessidade de decisão, e a posição do sujeito é insustentável, pois existe uma incompatibilidade de normas e os critérios normativos de resolução de conflitos (hierárquico, cronológico e especialidade) não solucionam o caso, tendo em vista que a fonte de ambas as normas é a própria Constituição Federal (DINIZ, 2003, p. 24-26).

Impende salientar que o caput do art. 166, da Constituição Federal, é claro ao estabelecer que os projetos de lei relativos ao plano plurianual, às diretrizes orçamentárias, ao orçamento anual e aos créditos adicionais serão apreciados pelas duas Casas do Congresso Nacional, na forma do regimento comum. Nota-se, neste ponto, que a lei orçamentária tem de ser apreciada pelas casas do Poder Legislativo. Em momento algum constou neste artigo a possibilidade de rejeição da LOA pelos parlamentares.

Aliás, ainda trazendo ao núcleo do estudo a letra fria da Constituição, é imperioso notar que o art. 35, $\S 2^{\circ}$, inciso III $^{2}$, do Ato das Disposições Constitucionais Transitórias (ADCT) não elencou outra hipótese senão a apreciação do projeto pelo Congresso, inclusive, frisando que a peça orçamentária deverá ser devolvida (e não rejeitada) pelo Legislativo.

A necessidade da existência anual da LOA ainda é perceptível quando se analisa sistematicamente a Constituição Federal, já que o art. 165, da Constituição ${ }^{3}$, faz menção expressa aos orçamento anuais.

Como já se viu anteriormente, foi a Lei n. ${ }^{\circ}$ 4.320/64 (que, embora se trate de lei ordinária, recebeu status de lei complementar, no momento em que foi recepcionada pela Carta Magna), em seu artigo segundo, que previu o princípio da anualidade do orçamento, ou seja, sobre a obrigatoriedade do orçamento ser renovado a cada ano. Desta feita, se a própria Constituição estabeleceu que caberia a lei complementar prever sobre a vigência da LOA, e a Lei n. ${ }^{\circ}$ 4320/64

\footnotetext{
${ }^{2}$ Art. $35[\ldots]$

“§ $2^{\circ}$ Até a entrada em vigor da lei complementar a que se refere o art. $165, \S 9^{\circ}$, I e II, serão obedecidas as seguintes normas: $[\ldots]$

III - o projeto de lei orçamentária da União será encaminhado até quatro meses antes do encerramento do exercício financeiro e devolvido para sanção até o encerramento da sessão legislativa". (BRASIL, 1988)

${ }^{3}$ Art. 165. "Leis de iniciativa do Poder Executivo estabelecerão:

I - o plano plurianual;

II - as diretrizes orçamentárias;

III - os orçamentos anuais.

$[\ldots]$

$\S 9^{\circ}$ Cabe à lei complementar:

I - dispor sobre o exercício financeiro, a vigência, os prazos, a elaboração e a organização do plano plurianual, da lei de diretrizes orçamentárias e da lei orçamentária anual". (BRASIL, 1988)
}

Revista de Direito Brasileira | Florianólopis, SC | v. 25 | n. 10 | p. 250-265 | Jan./Abr. 2020 
contemplou o princípio da anualidade do orçamento, a Constituição não poderia ter previsto a possibilidade da rejeição do projeto da LOA, pois, como pano de fundo, há a necessidade de existir um novo orçamento em todo ano.

Com efeito, não só em razão do princípio da anualidade que se depreende a obrigatoriedade da renovação anual do orçamento, mas também é possível enlaçar tal argumento sob a ótica do princípio da universalidade, abordado anteriormente. Se todas as receitas e despesas devem estar previstas no orçamento, de acordo com o que determina este princípio, caso não exista um orçamento (em virtude da rejeição da LOA, frise-se), tal princípio não será respeitado. A universalidade pressupõe a existência da lei orçamentária.

Com o intuito de robustecer a pesquisa, é imperioso que se traga à baila os argumentos (que correspondem a quantidade três) utilizados pelo doutrinador Dalmo de Abreu Dallari em seu trabalho intitulado Lei orçamentária - processo legislativo: peculiaridades e decorrências.

Inicialmente, o referido autor se apoia na interpretação do disposto no $\S 3^{\circ}, 166^{4}$, da Constituição Federal, que restringe a possibilidade de emendas à LOA. A redução do âmbito de emenda a LOA (que impede a elaboração de emenda que vise excluir a dotação para pessoal e seus encargos, serviços da dívida, e a transferências tributárias constitucionais) é um fator que deve ser ponderado quando se cogitar a rejeição total da LOA. Isso porque, de acordo com Dallari:

A simples leitura desse parágrafo mostra que é bastante limitado o poder de emenda. O que é uma rejeição senão a forma mais radical de emendar, suprimindo totalmente a regra inicialmente proposta! Ora, se a Constituição restringe o poder de emenda, que somente pode ser exercido dentro de certos limites, evidentemente proíbe, implicitamente, a emenda total, radical, modificadora absoluta do texto inicialmente proposto.

[...]

Com efeito, referido dispositivo limita o poder de opor emendas ao projeto de lei orçamentária, tornando insuscetíveis de supressão as despesas relativas à dotação para pessoal e seus encargos, bem como com relação ao serviço da dívida municipal, o que, em conseqüência, contraria a possibilidade de se rejeitá-las por completo. (DALLARI, 1996, p. 159)

Outro argumento utilizado pelo autor (e que, notadamente, demonstra o seu entendimento sobre a impossibilidade de se rejeitar in totum o projeto da LOA) é de que, nos termos do art. 100, $\S 5^{\circ 5}$, da Constituição Federal, é necessário tratar dos precatórios judiciais na LOA.

É hialino que aludida “dotação não pode ser reduzida, nem, muitíssimo menos, suprimida (o que fatalmente ocorreria em caso de rejeição do orçamento)" (DALLARI, 1996, p. 160). Dallari sustenta que "o veto total suprime dotações insuprimíveis, como é o caso da previsão de recursos

\footnotetext{
${ }^{4}$ Art. 166. [...]

" $\$ 3^{\circ}$ As emendas ao projeto de lei do orçamento anual ou aos projetos que o modifiquem somente podem ser aprovadas caso:

I - sejam compatíveis com o plano plurianual e com a lei de diretrizes orçamentárias;

II - indiquem os recursos necessários, admitidos apenas os provenientes de anulação de despesa, excluídas as que incidam sobre:

a) dotações para pessoal e seus encargos;

b) serviço da dívida;

c) transferências tributárias constitucionais para Estados, Municípios e Distrito Federal; ou

III - sejam relacionadas:

a) com a correção de erros ou omissões; ou

b) com os dispositivos do texto do projeto de lei”. (BRASIL, 1988)

5 Art. $110, \S 5^{\circ}$. "É obrigatória a inclusão, no orçamento das entidades de direito público, de verba necessária ao pagamento de seus débitos, oriundos de sentenças transitadas em julgado, constantes de precatórios judiciários apresentados até $1^{\circ}$ de julho, fazendo-se o pagamento até o final do exercício seguinte, quando terão seus valores atualizados monetariamente". (BRASIL, 1988)
}

Revista de Direito Brasileira | Florianólopis, SC | v. 25 | n. 10 | p. 250-265 | Jan./Abr. 2020 
para o atendimento de precatórios judiciais, do que resulta sua impossibilidade jurídica" (DALLARI 1996, p. 160).

Por fim, Dallari ainda discorre ser ilógico pressupor a possibilidade de criação de créditos especiais ou suplementares, sem existir um orçamento:

Note-se, também, que o supratranscrito $\S 8^{\circ}$ fala na utilização dos recursos que houverem ficado disponíveis "mediante créditos especiais ou suplementares". Ora, tais créditos são créditos orçamentários, o que pressupõe a existência de um orçamento. Não se abrem créditos no ar, no espaço, mas, sim, sempre, necessariamente, em um orçamento. (DALLARI, 1996, p. 160)

Constata-se que tais argumentos são plausíveis e se adéquam à lógica jurídica, porquanto: a) se determinadas matérias da LOA não são possíveis se modificar, por emenda, por qual razão seria possível a rejeição total do projeto? b) a questão dos precatórios judiciais (que variam de ano a ano) é um fator que impede a rejeição total da LOA; c) a criação de créditos orçamentários pressupõe, necessariamente, a existência de um orçamento.

Todavia, é essencial que se diga que também existem doutrinadores que entendem que a Constituição Federal permitiu a possibilidade da rejeição total da lei orçamentária anual, como é o caso de José Afonso da Silva (2014, p. 418):

A consequência mais séria da rejeição do projeto de lei orçamentária anual é que a Administração fica sem orçamento, pois não pode ser aprovado outro. Não é possível elaborar orçamento para o mesmo exercício financeiro. A Constituição dá a solução possível e plausível dentro da técnica do direito orçamentário: as despesas, que não podem efetivar-se senão devidamente autorizadas pelo Legislativo, terão que ser autorizadas prévia e especificamente, caso a caso, mediante leis de abertura de créditos especiais.

Por derradeiro, é importante que seja realizado um estudo reflexivo sobre o processo de criação de uma lei ordinária (gênero da qual a LOA pertence). Nos termos do art. 67 da Constituição Federal, "a matéria constante de projeto de lei rejeitado somente poderá constituir objeto de novo projeto, na mesma sessão legislativa, mediante proposta da maioria absoluta dos membros de qualquer das Casas do Congresso Nacional" (BRASIL, 1988).

Verifica-se que existe a possibilidade de o mesmo projeto de lei, que fora rejeitado, ser objeto de deliberação no mesmo exercício, desde que respeitado o quorum fixado pela constituinte. Ora, se para uma lei ordinária que trate de assunto diverso do orçamento, a fórmula para a sua reapreciação (dentro do mesmo exercício) é a prevista no art. 67, por que a lei orçamentária (uma das mais importantes dentre as espécies de lei ordinária) não poderia seguir esse padrão? A análise do art. 165, $\S 8^{\circ}$, da Constituição Federal, faz compreender que a hipótese de rejeição total da LOA ensejará a abertura de créditos especiais ou suplementares, portanto, não garante uma segunda chance ao projeto da LOA, diferentemente do que é garantido para qualquer outro objeto de lei ordinária. Ainda que se entenda pela possibilidade da rejeição total da LOA, a reapreciação do projeto, aos moldes do art. 67, também deve ser aplicada em matéria orçamentária.

Uma vez identificada a antinomia real, cabe apontar o caminho para sua resolução, produzindo uma aplicação jurídica adequada para as normas em tela. Os mecanismos para tanto se encontram previstos na Lei de Introdução às Normas do Direito Brasileiro, em seus arts. $4^{\text {o6 }}$ e $5^{\circ 7}$. Trata-se, assim, da analogia, dos costumes, dos princípios gerais do direito e da equidade, a serem utilizados nessa ordem no procedimento de integração. (DINIZ, 2002, p. 134-135)

${ }^{6}$ Art. 40. "Quando a lei for omissa, o juiz decidirá o caso de acordo com a analogia, os costumes e os princípios gerais de direito".

${ }^{7}$ Art. $5^{\circ}$. "Na aplicação da lei, o juiz atenderá aos fins sociais a que ela se dirige e às exigências do bem comum".

Revista de Direito Brasileira | Florianólopis, SC | v. 25 | n. 10 | p. 250-265 | Jan./Abr. 2020 
Cabe ao aplicador do direito, ante uma questão dúbia, indagar acerca da existência de disposição geral expressa e precisa sobre o tema; caso negativo, o técnico recorrerá aos preceitos sobre casos similares; se ainda assim não encontrar solução, irá até os costumes; na ausência destes, direcionará a busca para os princípios gerais; e, finalmente, não logrando êxito na utilização de tais instrumentos, far-se-á necessário o recurso à equidade. (DINIZ, 2002, p. 134 e 212)

Descartadas as hipóteses de aplicação de analogia e costumes no caso investigado, a solução se mostra clara com o recurso aos princípios. Os princípios gerais do direito são elementos normativos aplicáveis em casos concretos problemáticos, independentemente de restarem positivados, ou não, em normas, não sendo, portanto, meras máximas ou regras heurísticas. Possuem caráter geral, mas procedem de uma estimação objetiva, ética e social. (DINIZ, 2002, p. 233)

A rejeição total da LOA esbarra no princípio da eficiência da Administração Pública, previsto no art. $37^{8}$, da Constituição Federal. Isso porque, como é cediço, a eficiência "orienta a atividade administrativa no sentido de conseguir os melhores resultados com os meios escassos de que se dispõe e a menor custo. Rege-se, pois, pela regra da consecução do maior benefício com o menor custo possível ${ }^{9}$ " (SILVA, 2007, p. 337).

A edição de inúmeras leis visando à viabilização da execução orçamentária, nos casos de rejeição total da LOA, vai de encontro ao orçamento moderno, que beneficia o planejamento e a programação, mantendo-os como padrões, em nome do próprio desenvolvimento. Isso sem se cogitar na total paralisia do Poder Legislativo, que ficaria totalmente concentrado para a aprovação das referidas leis em substituição a LOA.

\section{CONCLUSÕES}

A lei orçamentária anual possui grande importância para a concretização de direitos essenciais à coletividade, tornando-se uma ferramenta para o desenvolvimento. É por intermédio dela que os direitos relativos à saúde, à educação, ao meio ambiente, à habitação, entre outros, são efetivados.

A iniciativa do projeto da LOA é do Poder Executivo, que deverá encaminhá-lo para apreciação do Poder Legislativo dentro do prazo fixado na legislação. Quando o projeto é encaminhado ao Legislativo, caberá à Comissão Permanente de Finanças, Orçamento e Economia a análise do projeto da LOA, que deverá fomentar a participação da população na audiência pública. Aliás, as fiscalizações promovidas pelos órgãos de controle, igualmente, são deveres essenciais para o perfeito delineamento da futura lei orçamentária.

Com efeito, os princípios orçamentários da unidade, universalidade, anualidade, legalidade, equilíbrio, programação orçamentária, exclusividade, publicidade são parâmetros previstos na legislação que devem ser observados para que todos os requisitos do projeto da LOA sejam preenchidos. Assim, percorrendo tal caminho, não há dúvidas que a lei orçamentária anual conduz a coletividade ao pleno desenvolvimento.

Contudo, constatou-se que as leis orgânicas dos municípios de Rio das Flores/RJ e de São Tiago/MG previram por artigos a possibilidade da rejeição total da LOA, oportunidade em que vigeria, para o ano seguinte, o orçamento do exercício em curso, sendo aplicada a atualização dos valores. Como se constatou, tais artigos foram declarados inconstitucionais, mas por argumentos distintos. Enquanto no primeiro caso argumentou-se que não seria possível a rejeição total do

\footnotetext{
${ }^{8}$ Art. 37. "A administração pública direta e indireta de qualquer dos Poderes da União, dos Estados, do Distrito Federal e dos Municípios obedecerá aos princípios de legalidade, impessoalidade, moralidade, publicidade e eficiência".

${ }^{9}$ Contudo, alerta Irene Patrícia Nohara que "[...] para melhor adequação do sentido jurídico da efíciência, faz-se necessária a adoção de um significado instrumental aos valores constitucionais, ponderando, portanto, com o juízo de razoabilidade diante da sustentabilidade e de orientação do Estado para a efetividade do bem comum" (NOHARA, 2016, p. 147).
} 
projeto da LOA, no segundo, houve a alegação de que a inconstitucionalidade decorreu da não observância do procedimento disposto no $\S 8^{\circ}$, do art. 166, da Constituição Federal. Segundo tal dispositivo, os recursos que, em decorrência de rejeição do projeto de lei orçamentária anual, ficarem sem despesas correspondentes poderão ser utilizados, conforme o caso, mediante créditos especiais ou suplementares, com prévia e específica autorização legislativa.

Não obstante a letra fria do $\S 8^{\circ}$, do art. 166, da Constituição Federal traga a possibilidade de rejeição total da LOA, nota-se que tal dispositivo está em conflito com o art. $35, \S 2^{\circ}$, inciso III, 165 e 166, caput, também da Carta Magna, assumindo tal confronto a magnitude de antinomia real, ensejando a colmatação nos moldes do art. $4^{\circ}$, da Lei de Introdução às Normas do Direito Brasileiro.

Conclui-se, dessa forma, que, pela aplicação do princípio da eficiência da Administração Pública, não é cabível a rejeição total da LOA, pois isto geraria um aumento de trabalho e de gastos consideráveis ao Poder Legislativo, o qual teria que aprovar pormenorizadamente cada despesa do Executivo. Tal perspectiva atinge, ainda, o próprio direito ao desenvolvimento, porque a inexistência de um orçamento impede o perfeito planejamento no tocante às necessidades momentâneas da coletividade.

\section{REFERÊNCIAS}

BALEEIRO, Aliomar. Uma introdução à ciência das finanças. 10 ed. Rio de Janeiro: Forense, 1969.

BARRAL, Welber. Direito e desenvolvimento: um modelo de análise. In: Direito $e$ Desenvolvimento: Análise da ordem jurídica brasileira sob a ótica do desenvolvimento. Welber Barral (Org.). São Paulo: Editora Singular, 2005.

BRASIL. Constituição (1988). Constituição da República Federativa do Brasil. Disponível em: <http://www.planalto.gov.br/ccivil_03/constituicao/constituicao.htm>. Acesso em: 03 dez. 2018.

DALLARI, Dalmo de Abreu. Lei orçamentária - processo legislativo: peculiaridades e decorrências. Brasília a. 33 n. 129 jan./mar. 1996. Disponível em:

<http://www2.senado.leg.br/bdsf/bitstream/handle/id/176389/000506406.pdf?sequence=1 > . Acesso em: 18 dez. 2018.

DEVIDES, José Eduardo Costa; SILVEIRA, Daniel Barile da. O accountability, a transparência pública e o direito humano ao desenvolvimento. Disponível em:

$<$ https://periodicos.unipe.br/index.php/direitoedesenvolvimento/article/view/417/339>. Acesso em: 18 dez. de 2018.

Lei n. ${ }^{\circ}$ 4.320, de 17 de março de 1964. Estatui Normas Gerais de Direito Financeiro para elaboração e contrôle dos orçamentos e balanços da União, dos Estados, dos Municípios e do Distrito Federal. Disponível em: 〈http://www.planalto.gov.br/ccivil_03/LEIS/L4320.htm>. Acesso em: 12 dez. 2018.

BULOS, Uadi Lammêgo. Direito Constitucional ao Alcance de Todos. Saraiva, 4. ed. São Paulo: Saraiva, 2012.

CAMPELLO, Lívia Gaigher; SANTIAGO, Mariana Ribeiro; ANDRADE, Sinara Lacerda. A valorização da identidade cultural como desafio à concretização do direito ao desenvolvimento. Revista de Direito Brasileira. São Paulo, SP, v. 19, n. 8, p. 3- 19, Jan./Abr. 2018. 
DINIZ, Maria Helena. As lacunas do direito. 7 ed. atual. São Paulo: Saraiva, 2002.

DINIZ, Maria Helena. Conflito de normas. 5 ed. aum. e atual.. São Paulo: Saraiva, 2003.

ENGISCH, Karl. Introdução ao pensamento jurídico. Trad. J. Baptista Machado. 8 ed. Lisboa: Fundação Calouste Gulbenkian, 2001.

FERRAZ JUNIOR, Tercio Sampaio. Introdução ao estudo do direito. 6 ed. rev. e ampl. São Paulo: Atlas, 2012.

GIACOMONI, James. Orçamento público. 16. ed, São Paulo: Atlas, 2012.

GONTIJO, Vander. Princípios orçamentários. Brasília: Câmara dos Deputados, 2004.

Disponível em: <http://www2.camara.leg.br/orcamento-da-

uniao/cidadao/entenda/cursopo/principios.html>. Acesso em: 14 dez. 2018.

HARADA, Kiyoshi. Direito financeiro e tributário. 18. ed. São Paulo: Atlas, 2009.

LARENZ, Karl. Metodologia da ciência do direito. Tradução José Lamego. 3 ed. Lisboa: Fundação Calouste Culbenkian, 1991.

LUÑO, Antonio-Enrique Pérez. La seguridad jurídica, Barcelona: Ariel, 1991.

MARTINELLI, Adriano Justi. O direito humano e fundamental ao desenvolvimento e o seu regime jurídico. 2013. Disponível em:

<http://www.abdconst.com.br/revista8/direitoAdriano.pdf>. Acesso em: 17 dez. 2018.

MARTINS, Ives Gandra da Silva; GODOY, Mayr. Tratado de Direito Municipal. Vol. I. São Paulo: Quartier Latin, 2012.

MEIRELLES, Hely Lopes. Direito municipal brasileiro. 18. ed. São Paulo: Malheiros, 2017.

MINAS GERAIS. Tribunal de Contas do Estado. Parecer relativo à inspeção extraordinária realizada na Prefeitura Municipal de São Tiago, decorrente de denúncia encaminhada pelo Promotor de Justiça da Comarca de Bom Sucesso. Disponível em:

<http://tcnotas.tce.mg.gov.br/tcjuris/Nota/BuscarArquivo/17947>. Acesso em: 21 dez. 2018.

NOHARA, Patrícia Irene. Reforma administrativa e burocracia. São Paulo: Atlas, 2016, p. 147.

ORGANIZAÇÃO DAS NAÇÕES UNIDAS. Assembleia Geral. Declaration on the Right to Development. A/RES/41/128, de 4 de dezembro de 1986. Disponível em:

<http://www.un.org/documents/ga/res/41/a41r128.htm>. Acesso em 17 dez. 2018.

REALE, Miguel. Lições preliminares de direito. 27 ed. atual. 7 tir. São Paulo: Saraiva, 2002.

SADECK, Francisco. Orçamento público e fundos dos direitos da criança e do adolescente. In: ASSIS, S. G., ET al., orgs. Teoria e prática dos conselhos tutelares e conselhos dos direitos da criança e do adolescente [online]. Rio de Janeiro: Fiocruz, 2009, p. 255-286. Disponível em: <http://books.scielo.org/id/3svc2/pdf/santos-9788575415962-07.pdf>. Acesso em: 14 dez. 2018. 
SAVIGNY, Friedrich Carl Von. Metodologia jurídica. Tradução Hebe A. M. Caletti Marenco. Campinas, SP: Edicamp, 2001.

SEN, Amartya. Desenvolvimento como liberdade. São Paulo: Companhia das Letras, 2010.

SEN, Amartya. Reforma jurídica e reforma judicial no processo de desenvolvimento. Tradução Welber Barral. In: Direito e Desenvolvimento: Análise da ordem jurídica brasileira sob a ótica do desenvolvimento. Welber Barral (Org.). São Paulo: Editora Singular, 2005.

SICHES, Recaséns. Nueva filosofía de la interpretación del derecho, 2 ed. ampl., México: Porruá, 1973.

SILVA, José Afonso da. Comentário Contextual à Constituição. 3. ed. São Paulo: Malheiros, 2007.

SILVA, José Afonso da. Teoria do Conhecimento Constitucional. São Paulo: Malheiros, 2014.

SILVEIRA, Vladmir Oliveira da e NASPOLINI, Samyra Haydée Dal Farra. Direito ao desenvolvimento no Brasil do Século XXI: uma análise da normatização internacional e da Constituição brasileira In: Direito e desenvolvimento no Brasil no Século XXI. Vladmir Oliveira da Silveira et al. (orgs.). Brasília: Ipea/CONPEDI, 2013.

RIO DE JANEIRO. Tribunal de Justiça do Estado. Ação direta de inconstitucionalidade n. ${ }^{\circ}$ 0047431-11.2012.8.19.0000. Relator Des. Edson Queiroz Scisinio Dias. Pesquisa de jurisprudência, Acórdãos, 10 setembro 2014. Disponível em: <http://www4.tjrj.jus.br/ejuris/ConsultarJurisprudencia.aspx>. Acesso em: 22 dez. 2018. 